\title{
The Brand Construction of Campus Culture with the Opportunity of Humanistic Spirit Cultivation
}

\author{
Meiping Lv \\ Xinchang College of Zhejiang Radio and Television University, Xinchang, China \\ Email: 924409163@qq.com
}

How to cite this paper: Lv, M.P. (2020) The Brand Construction of Campus Culture with the Opportunity of Humanistic Spirit Cultivation. Open Access Library Journal, 7: e6014.

https://doi.org/10.4236/oalib.1106014

Received: December 20, 2019

Accepted: January 11, 2020

Published: January 14, 2020

Copyright $\odot 2020$ by author(s) and Open Access Library Inc.

This work is licensed under the Creative Commons Attribution International License (CC BY 4.0).

http://creativecommons.org/licenses/by/4.0/

\begin{abstract}
Education is an activity to cultivate people. No matter in what time and in what form, the education should put morality and ability first, and develop the people in the first place. So it is particularly important in the transformation and development process of TVU to build campus cultural brand with the opportunity of humanistic spirit cultivation. Xinchang College of Zhejiang Radio and Television University has made a series of effective attempts to create a long-term mechanism by using its advantageous resources.
\end{abstract}

\section{Subject Areas}

Education, Journalism and Communication, Sociology

\section{Keywords}

Humanistic Spirit Cultivation, Campus Culture Brand, TV University

\section{Introduction}

Education is an activity to cultivate people. No matter in what time and in what form, the education should put morality and ability first, and develop the people in the first place. The campus culture of a university is the soul of a university. It is the source to stimulate the vitality of college students, and plays an important role in cultivating new college students and shaping their soul. Therefore, it is very important to cultivate the humanistic spirit to build the uniqueness and effectiveness of campus culture [1]. 


\section{The Necessity for TVU to Build a Cultural Brand in Educational Campus with an Open Mind}

1) Meeting the opportunities and challenges of TVU's transformation and development

It is the historical choice to build an open university on the basis of TVU under this new situation. This transformation is reflected in many aspects, such as school running concept, school running mechanism, technical service, system guarantee, etc. In terms of concept, on the one hand, the radio and television university will continue to adhere to popularization, good service awareness and school quality. On the other hand, it will make greater efforts to enrich the complete significance of universities, including the nature of "higher level of education" and "academic level". As for the school running mechanism, the radio and television university integrates social high-quality education resources. And taking strategic cooperation as the link, it will establish various cooperation alliances with urban and rural areas, universities, industries and enterprises, in order to constructs "flyover" in the sense of a lifelong education that "everyone can learn at any time and in any place". For the technical services, the university pays attention to the deep integration of modern science and education. Through the full usage of satellite, TV, Internet, mobile terminals and cloud computing, it carries out academic education and non-academic education to realize "ubiquitous learning". Meanwhile, in regards of institutional guarantee, the university will have a further clear understanding of its functional orientation, development objectives and organizational structure. What's more, it will clarify the relationship among all levels and entities within the system, and handle its relationship with social environment and relevant units to ensure that it can develop in a healthy and open way.

As far as TVU of our province is concerned, it is facing new and excellent opportunities for development, due to the superposition of many factors. First, the party and government attach great importance to education. Secondly, the profound changes have taken place in the major social contradictions of our country. Thirdly, it has been comprehensively implemented that the strategy of strengthening the province through higher education. At the same time, TVU of our province is also facing challenges from both inside and outside the system, which need to be jointly faced and solved by the whole system. It is the development orientation and transformation goal of TVU to build open universities of Zhejiang in a "high level", as well as be committed to become the core pillar of life-long education in Zhejiang Province and the service center of distance open education, which is also TVU's new mission. Therefore, great emphasis must be paid to the construction of campus culture campus in the process of building open universities of Zhejiang and the overall transformation of TVU system. Joint efforts should be made by the whole system of TVU.

2) Providing cases and models of cultural and spiritual construction for the new education and learning mode 
TVU has a long history in adult distance education, and has formed a relatively mature teaching and management mode. With the progress of the times, however, modern distance education has become a common educational form and the main means to build people's lifelong learning system, whether it is schools, communities, or other institutions involved in education and teaching. This kind of educational learning mode is characterized by the systematic teaching and communication between students and teachers or students and educational institutions are through the multimedia tools. In the whole learning period, students mainly exist in the form of individuals, which allows students to study without learning groups and in the separation of teachers for permanent time. Therefore, while fully showing its advantages such as not limited by time and space, free arrangement of learning time, it also highlights the shortcomings of the lack of mutual understanding between teachers and students, students and students, as well as the lack of humanistic care and spirit embodied in traditional education between teachers and students or among groups.

No matter what kind of "separation" and "allowed separation", as long as there are educational activities or bilateral interactions between educators and educated, it must also need cultural maintenance, even for a school without walls. Humanistic spirit is indispensable to a school. As open distance education school for a long time, TVU has the responsibility to provide experience and model for more and more educational units involved in this field and mode.

3) Exploring the connotation and ways of humanistic spirit cultivation in adult education

As a universal human self-care, humanistic spirit refers to the maintenance, pursuit and concern of human dignity, value and destiny, and the high value of various spiritual. It is the cultural phenomena left behind by human beings, and the affirmation and shaping of an ideal personality with all-round development. School education is one of the important ways to nurture the humanistic spirit. And it undertakes the mission of excellent cultural heritage together with family education and social education.

The cultivation of humanistic spirit is also a systematic project. There are different emphases and preferred ways in different stages of school education. It affects not only the educated but also the educator and the school itself. In fact, the cultivation of humanistic spirit is an advanced form of campus culture. A good humanistic spirit, on the one hand, can enable teachers to devote themselves to work and enjoy the work fun from education and teaching on the other hand, it helps students to devote themselves to study, forming a learning atmosphere of love, pleasure and interest, and helps them to cultivate a good collective consciousness. A good collective consciousness is a kind of intangible positive group norm, and an invisible and huge force for teachers' professional ethics and students' ideological and moral character. It helps teachers and students to achieve close cooperation and learn from each other in education and teaching activities, forming a united and harmonious collective, which is good for the better overall effect, and positive energy for the society. Relatively speak- 
ing, how to grasp the cultivation of humanistic spirit in adult schools in the past has not been paid much attention. Therefore, it is particularly necessary to study and practice.

\section{Exploration and Practice by Xinchang College of RTVU}

1) Building the campus spiritual culture of "TVU's students brand" with the power of example

As a macro concept of people-oriented, respecting and exerting human value, and consciously pursuing the beauty and significance of life, "humanistic spirit" needs to be endowed with specific connotation featuring times and nationality in specific historical circumstances. It affects the cultural environment, and then shape a new human spirit through the transformed cultural environment, thus forming a reasonable, healthy, harmonious, and beautiful spiritual culture, as well as a positive, mutually beneficial, healthy and harmonious cultural atmosphere.

All links and regions of society need spiritual culture with deep human feelings. Especially campus spiritual culture is the core of campus culture, the soul of the school, and the centralized reflection of the essence, personality and spiritual outlook of a school. It mainly includes the historical tradition of the campus and the common cultural concepts, values, life concepts and other ideologies recognized by all teachers and students, which is a concentrated reflection of the essence, personality and spiritual outlook of a school [2].

Since 2005, Xinchang College has been focusing on the construction of campus spiritual culture. TVU has various forms of running schools, complex types of students, and different years of students in school, which requires the spiritual cultivation of "humanity" to coordinate the development of all kinds of education in connotation construction, especially a campus spiritual culture recognized by teachers and students. The concept that can not only reflect the historical tradition of the campus, but also be recognized by the majority of teachers and students must be connected with the achievements, difficulties and bright future that TV university students and teachers create together. Therefore, we investigate, understand, sort out and explore the extraordinary deeds of "RTVU people" in ordinary posts over the years, as well as set up the typical of excellent students, in order to build "RTVU people brand". And we want to provide all RTVU students with a learning opportunity of culture and ceramics, and better stimulate their enthusiasm in work, study and life since they will feel inspired in the RTVU collective. The purpose of setting up a good example is to pay attention to the exemplary leading role of the students. And it can transform the typical process of setting examples into a process of conscious learning, active publicity and hard work, which will promote the cultivation of the school's humanistic spirit, and form a harmonious interpersonal relationship and civilized campus fashion. We believe that the core of humanistic spirit is the world outlook, outlook on life and values; many students of RTVU pay attention to their 
own, social and human development in their work and daily life, and work hard for it, which is the "the most beautiful effect" that "RTVU brand" can produce.

In the process of building the brand, Xinchang College emphasizes the practical education activities themed "example around us". From September 2011 to December 2019, more than 80 student models have been set up. These role models are ordinary and amicable with touching stories behind them. So that teachers and students all learn from them and follow their examples. For example, comrade Lv Weixing, a member of the Communist Party of China (CPC) and a second-class police supervisor, is a member of the traffic police brigade of Xinchang County Public Security Bureau. He studied law in Xinchang branch of RTVU in July 2001 and graduated in July 2004. Because of his outstanding work, he won the honorary titles of national advanced worker and national excellent people's police in 2015, and was selected as one of "one hundred outstanding alumni of Zhejiang Radio and Television University". His deeds were selected and published in “Outstanding Alumni's Demeanor Record", as well as reported twice by CCTV. Xinchang College regards him as an example of the campus. For one reason, his growth is connected with the development of TVU. On the other hand, Lv Weixing, who has won many honors, continues to struggle for his extraordinary life legend in his ordinary post: every day. In detail, he appears at the intersection of the gate of Chengxi primary school, Gushan West Road. At that place, when he saw the elderly and children, he carefully helped them cross the road. When he saw traffic violations, he still carried out strict and standardized education and punishment. He is the "road Baogong", that is to say he strictly follows the rules in the work. His spirit embodies the ideological quality of RTVU people, which is diligent, persistent, effective and beneficial to the people.

2) Changing the relative isolation of "human and machine" communication with the concept of service

TVU is an adult university, which attaches equal importance to both academic and non-academic education. In a real sense, it is an open and social university. No matter in the teaching and management, or in the construction of campus culture, the carrier of communication between teachers and students mainly relies on remote and network media. Most of teachers and students are separated in time, space and psychology, which means the characteristics of virtualization are obvious. The communication, between teachers and students or among students, is easy to become the communication between people and machines, lacking the emotional communication in other common campuses, with the weak sense of "integration" and "participation".

In order to change such situation, Xinchang College proposed that "great efforts should be made to improve the teaching management of TV University as ordinary high school, the practical skill training of TV University staff as vocational high school, and the humanistic care of TV University students as backward students". It calls on all staff to "always cherish the heart of service, always practice the skill of service, often string the door of students", and establish the 
service concept of "all for students".

The college actively carries out various colorful class activities in order to increase the opportunities for the students and teachers to communicate with each other in real life. It carries out humanistic care with careful consideration, to completely change the situation of "people and machines". All of these are to sincerely serve the majority of students, so they win the praise of students. The cultivation of humanistic spirit shows the increasingly good effect. And the moving deeds of "models around us" become the driving force for the majority of students to move forward. What's more, the students deeply understand that interpersonal relationship is essentially inseparable in TV University both in the time and space, fortunately, the stage of TV University is full of humanistic care, which is enough to make every TV adult more brilliant.

The construction of campus culture brand is of great significance to expand the social influence and promote the development of school connotations. Xinchang College has won high praise from all walks of life. It has successively won more than 90 collective honors, including China's education reform and Innovation Demonstration College in the 21st century, excellent training institutions of national continuing education, provincial demonstration county-level TV University, advanced collective of ideological and political education of TV University of the whole province, advanced school running unit of TV University System of the whole province, advanced collective of scientific research of TV University of the whole province, and advanced collective of adult education of Shaoxing City. The practice of Xinchang College to build campus culture brand with "model around us" has been reported in many platforms such as China Education Daily, Guokai University news network, provincial radio and TV University website, Xinchang news, Xinchang daily and so on.

\section{The Long-Term Mechanism Established by the School in the Cultivation of Humanistic Spirit}

As the internal mechanism of campus culture, campus system culture is the essential guarantee mechanism to maintain the normal operation of the school, which plays the role of cognitive orientation, emotional cultivation and behavioral norms. The school management system, a kind of campus culture, must be based on its own culture, serve its own campus spiritual culture, and well reflect and integrate the school running thoughts and ideas. A good system should move from text to culture. Whether the system is a culture or not, the most important thing is to see whether the system that embodies the school running thought, idea and spirit can be actually implemented. Therefore, in the comprehensive promotion of the construction of campus system culture, Xinchang College has made hard efforts in the two following aspects with persistence: "establishing and improving various management systems" and "strengthening and improving the construction of corresponding organizations and teams". Concrete implementation has been carried out in the functional division of all de- 
partments of the college. More efforts will be made to strengthen the supervision and implementation of various systems so as to make the system deeply rooted in the hearts of the people, internalize it into the code of conduct of all teachers and students of the University, as well as form the campus system culture. Based on the management of the school, the construction of the school system which embodies the concept of governing the school according to law emphasizes the combination of people-oriented thought and scientific management means to establish a system culture with human feelings, innovative vitality and team spirit to develop human subjectivity and enhance human life value.

1) Setting up plans and schemes

At present, the concept of TVU system is unchanged, but the development of TVU is in the process of transformation. In the instructions of the Provincial Radio and Television University, there are some points that are particularly stressed. First, continuous struggle should be made for the construction of open universities. The establishment of Zhejiang Open University on the basis of Zhejiang Radio and Television University has been listed in the provincial "13th five-year plan" for the establishment of institutions of higher learning. And in the name of the provincial government, the Ministry of Education has been invited for this visit. We should continue to strengthen the connotation construction in accordance with the 12 tasks proposed in The Opinions on Running Open Universities issued by the Ministry of Education. Second, we will continue to promote business. The enrollment of open education, adult education and other academic education is getting better. Great achievements have been made in community education, elderly education and other non-academic education. We should focus on problems, strengthen overall planning, coordinate development, and firmly establish the main business awareness and brand awareness.

To adhere to the goal of strategic transformation, we must strengthen the connotation construction. And the cultivation of humanistic spirit is particularly important in the construction of TV university campus cultural brand in the transformation, so we should establish a long-term mechanism. For this reason, Xinchang College has formulated specific activity plans, holds a class teacher meeting of "models around us" every month, and implements specific measures.

2) Selecting topics and examples

The teacher in charge of the class shall convene class meeting with a specific theme to study and implement the spirit of the document, and select the class role models. The class shall be selected in groups to set up advanced models such as learning model, integrity model, helping model, filial piety model and entrepreneurship model. The selected model must have supporting materials. According to the recommendation of the group, the class will make a comprehensive evaluation, and decide the recommended model by way of speech or research, which will be reported by the head teacher.

Because of the standard, conditions and rich types of the model, it has a great impact on teachers and students. For example, Wang Yongfu, a "model of help- 
ing others", graduated from the rural administration specialty class in the 10th spring, and then studied in the horticulture undergraduate class in the 17th autumn. Since 1999, he has joined the team of blood donation for free. In 2009, he became a three-star volunteer. In 2010, he became the annual champion of Shaoxing City and promoted to a five-star volunteer. Over the past 10 years, his cumulative blood donation has reached $28000 \mathrm{ml}$. In addition to going to Shaoxing to donate blood every month, Wang Yongfu often popularized the knowledge of blood donation to the people around him to eliminate their fear of blood donation. Under his influence, his brothers, RTVU students, colleagues and even his customers all joined in the team of free blood donation. Wang Yongfu said: "I would like to have more new faces join the team of free blood donation, so that the scale of this team can grow up and light more wonderful life with more blood."

3) Social appraisal and school commendation

The Academic Affairs Office shall convene a class teacher meeting in order to conduct comprehensive analysis, conduct social assessment survey (including the survey of students' own unit, the survey of people around them and the household registration survey of students), and finally determine the "models around us". A commendation conference was held, and the theme education of "models around us" was carried out at the opening ceremony of each semester. Specially, we invited those models selected in the activity of "models around us" to give an appearance speech for TVU freshmen to give them a sense of belonging.

For example, Tao Guojie, deputy middle captain of Chengdong squadron of Zhuji City fire brigade in Zhejiang Province, is a 2009 spring administrative management undergraduate of Xinchang University. On March 10, 2012, in a fire fighting, Tao Guojie suffered brain injury and severe burn of airway. Tian Sijia, the deputy instructor with him, made a glorious sacrifice after full rescue. Xinchang College sent out an initiative to all teachers and students to learn from the firefighters represented by Tao Guojie. The proposal puts forward that we should learn from the heroes around us. We should learn their revolutionary spirit of devotion, dedication and selfless dedication, as well as learn their noble sentiments that they are not afraid of hardship and death, and serve the people wholeheartedly. We hope that this spirit and sentiment will run through our ordinary work, contribute to the construction of a harmonious society and strive for the rejuvenation of China.

4) Based on the local area and serving the society

The construction of campus culture should not only carry forward the characteristics of the times, but also closely integrate with the local development in reality and serve the local economy. For this reason, Xinchang College carries out a series of activities with the theme of "seeking knowledge, starting a business and becoming rich" every month, looking for the most beautiful peasant college students and promoting the elegant demeanor of TVU's students. 
In this process, many entrepreneurial models with local characteristics have emerged. For example, Wu Yumei, a junior college student majoring in pre-school education in the 13th spring of TVU and a horticultural undergraduate in the 17th autumn, won the silver medal in the 2015 national tea artist skills competition and the first prize in the Zhejiang tea artist skills competition after the school's guidance. Wu Lianlian, a student, won the silver medal in the 2019 national tea artist skills competition and the first prize in the 2018 Zhejiang tea artist skills competition, becoming a flagpole for college students to return home and start their own businesses; And Shi Dandan, a 16 autumn landscape technology college student, was trained by the college and won the first place in the 2016 Shaoxing vocational skills competition and the first place in the group. At present, he has registered two domestic service companies and become a brand of zero capital entrepreneurship. There are many other examples like these. Through publicity and learning, Xinchang College has made the deeds of role models infect the students of TVU. It has made more people know the excellent role models and let the students be proud of "I am a person of TVU".

5) Rich means and diversified dissemination

The school will make special films with the most influential and guiding role of excellent models, so that the students of RTVU can be cultivated with humanity. Every month, we will make a special edition of "models around us" to show and publicize in the school. And activity of the "models around us" will be publicized and reported online in the "TVU people's demeanor" column of the school website and rewarded every month.

The construction of campus culture should be the joint efforts of college students and colleges. Campus culture is the source of strength that universities never fail, and plays an important role in cultivating the core competitiveness of education. Teaching equipment, management procedures and human resources of a school can be introduced, but its cultural character is unique and cannot be introduced. Nowadays, the hardware construction, school running idea, management mode and teaching mode are converging day by day. Whether the cultural character of campus is distinct and whether the cultural vitality is vigorous has become a key factor to build a high-quality brand of campus culture [3].

Campus culture brand is an important embodiment of the characteristics of a school. Once formed, it will have a profound impact on the development of the school. Xinchang College nurtures the brand construction through humanistic spirit, which makes the brand construction of campus culture have a more profound effect.

The society calls for the return of noble moral quality, and it is urgent to enhance positive energy and create a harmonious, healthy and positive social atmosphere. In line with this trend, Xinchang College guides, influences, inspires, shapes, changes and develops people through the education activity themed "models around us", which practically makes every student of RTVU enjoy the cultivation of spirits. It also enables every student to bear the mission and re- 
sponsibility given by the times, and fully demonstrates the style of role models of Xinchang RTVU's students. Xinchang College will adhere to the consistent fine style, continue to pay attention to the cultivation of humanistic spirit, form a harmonious interpersonal relationship and civilized campus fashion, and build a vibrant and dynamic county-level TV university.

\section{Conflicts of Interest}

The author declares no conflicts of interest regarding the publication of this paper.

\section{References}

[1] Xu, B.C. (2010) Thinking and Exploration on the Construction of Campus Culture Brand in Colleges and Universities, Also on the Construction of Campus Culture Brand in Xiamen Institute of Technology. Young Litterateur, No. 9, 258-259.

[2] Shao, D.R. (2012) On the Construction of Campus Culture Brand. China Science and Technology Wealth, No. 10, 486.

[3] Liu, L. (2014) Reflections on the Construction of Campus Culture Brand. Journal of Jilin Education Institute, No. 8, 19-20. 